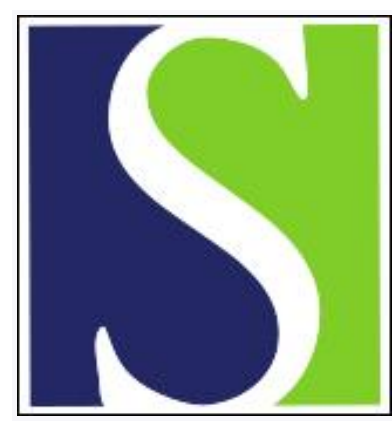

Scand J Work Environ Health 1999;25(6):521-528

https://doi.org/10.5271/sjweh.475

Issue date: Dec 1999

\title{
Biomarkers and their use in occupational medicine
}

by Aitio $A$

The following article refers to this text: $2004 ; 30(1): 1-3$

Key terms: biomonitoring; chemical hazard; exposure assessment; health surveillance

This article in PubMed: www.ncbi.nlm.nih.gov/pubmed/10884148

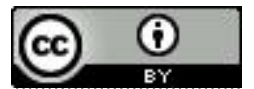




\title{
Biomarkers and their use in occupational medicine ${ }^{1}$
}

\author{
by Antero Aitio, $M D^{2}$
}

\begin{abstract}
Aitio A. Biomarkers and their use in occupational medicine. Scand J Work Environ Health $1999 ; 25(6$, special issue): $521-528$.

Biomarkers of exposure, parent chemicals, metabolites, and also hemoglobin and DNA (deoxyribonucleic acid) adducts, even urinary mutagenicity, have been used successfully to identify exposed persons, follow-up exposure, and quantitatively assess exposure. Some have been validated as indicators of health risk. The avenues for future biomarkers of exposure are in the development of robust, simple, and inexpensive semiquantitative methods for daily use on every worker for assuring that no (excessive) exposure takes place. Some biomarkers of effect have also been well validated and are widely used in routine monitoring activities. However, with the exception of cholinesterase inhibitors, biomarkers of effect offer little advantage over the analysis of the chemical itself. Their use will be limited to carefully planned ad hoc studies. Biomarkers of susceptibility currently have no practical application in worker health protection. Biomarker research should concentrate on validating methods, in terms of the prediction of health effects, and on elucidating exposure-biomarker concentration relationships.
\end{abstract}

Key terms biomonitoring, chemical hazards, exposure assessment, health surveillance.

\section{Biomarkers of exposure, effect and susceptibility}

The Committee on Biological Markers in Environmental Health of the United States National Academy of Sciences and National Research Council have defined 3 different types of biomarkers, namely, markers of exposure, effect and susceptibility (1). A biomarker of exposure was defined as an exogenous substance within the system, the interactive product between a xenobiotic compound and endogenous compounds or some other event in the biological system related to the exposure. Biomarkers of effect were defined as indicators of an endogenous component of the biological system, a measure of the functional capacity of the system, or an altered state of the system that is recognized as impairment or disease. Biomarkers of susceptibility were defined as indicators that the health of the system is especially sensitive to the challenge of exposure to a xenobiotic compound. This nomenclature has then been widely adopted (2). Biological monitoring in occupational health is the application of biomarkers of exposure or effect. Biomarkers of susceptibility have so far had little application, but they have been extensively discussed, mainly because of the ethical problems involved. In the present review, I try to present the status and future trends of the 3 types of biomarkers in occupational health practice in a structure in which the main uses of biomarkers (ie, identification and quantitation of exposure and identification and quantification of health risks) are separated.

\section{Biomarkers of exposure}

\section{Identification of exposure}

Most biomarkers of exposure are well suited for the identification of exposed individuals and groups. However, it requires analytical and metabolic specificity. Source specificity is a further important consideration.

Analytical specificity refers to the capacity of the analytical method to measure exclusively the chemical that it purports to measure. Metabolic specificity refers to the extent that the analyte measured is derived from the parent chemical of interest. Source specificity is crucially important from the point of view of prevention even though people are exposed to many chemicals of interest in occupational health also from other sources, such as ambient air or diet, and, apparently, the chemicals have

1 Parts of this article are based on 2 IPCS documents that are in preparation: "IPCS Guidelines for the Monitoring of Genotoxic Effects of Carcinogens in Humans" and "Biomarkers in Risk Assessment: Validity and Validation". The views presented, however, are solely those of the author. Finnish Institute of Occupational Health, Helsinki, Finland.

Reprint requests to: Dr Antero Aitio, International Programme on Chemical Safety, WHO, Avenue Appia 20, CH-1211 Genève 27, Suisse. [E-mail: Antero Aitio@who.ch] 
similar effects irrespective of the source of exposure. Biomarkers of exposure are not capable of identifying the source of the chemical, however. Thus the identification of the exposure depends on the concentration difference between the exposed individual and the general population (ie, it is based on the comparison of the result with reference values derived from an appropriate population). When the occupational exposure is high, it is easy to detect, but, when it is low, biomonitoring is no longer capable of distinguishing the occupational exposure. This situation has important implications on the methods used. At high occupational exposure levels even methods that have low metabolic (and even analytical) specificity can be useful tools in biomonitoring, while at low relative exposures they are not useful.

\section{Quantitative exposure assessment}

Quantitative exposure assessment is based on knowledge of the relationship between the measured external exposure and the biomarker. This information is well advanced for many chemicals that are mainly absorbed in the body via inhalation, for example, styrene $(3-8)$. On the other hand, for several chemicals, for example, dimethylformamide (9-13), the picture is less clear. Different studies on the relationship between exposure, and the biomarker concentration have yielded widely different results. Thus the uncertainty of exposure assessment from biomonitoring varies considerably between different chemicals.

When the absorption is (mainly) dermal, there is at present no reliable approach to assess the relationship between exposure or absorbed dose and biomarker concentration. This is an unfortunate situation, since biomonitoring would be very useful for the assessment of dermal exposure; also it is apparent that for many chemicals with low vapor pressure, dermal exposure is very important.

The disappearance rate from the body after the cessation of exposure varies widely among different chemicals. This rate has important implications for the interpretation of biomonitoring analysis; for chemicals with a half-time of less than 2 hours, meaningful biomonitoring is not feasible. When the half-time is on the order of $2-10$ hours, a sample collected at the end of the workday reflects the exposure over the day, while, with halftimes of 10-100 hours, the optimal sampling time is at the end of the workweek, and the results reflect exposure during the preceding few days (14). Consequently, the shorter the half-time, the more frequent the sampling should be to give a representative picture of the exposure.

Macromolecule adduct measurements have been proposed as biomarkers of exposure to genotoxic carcinogens. The most widely applied approaches have been measurements of adducts in hemoglobin and lymphocyte
DNA (deoxyribonucleic acid) (15). Both have been successfully used for the identification of exposed people and as short-term indicators of the effects of intervention (16).

The advantages of hemoglobin adducts include the well established kinetics in that there are no repair enzymes that would remove the adduct once it has been generated. Most adducts arise from the same metabolic pathways as DNA adducts and thus levels of DNA and hemoglobin adducts - are likely to correlate, as has been demonstrated in the case of ethylene oxide. For some chemicals, notably alkenes and aromatic amines, information is available on the quantitative relationship between exposure and hemoglobin adducts $(17,18)$.

The analysis of DNA adducts in peripheral blood white cells (lymphocytes or granulocytes) has been the most extensively studied among people exposed to polycyclic aromatic hydrocarbons $(\mathrm{PAH})(15,19)$. Elevated DNA adduct levels have been observed among workers in coke, aluminum, and electrode production, chimney sweeps, and diesel-exhaust-exposed car mechanics and bus drivers. Elevated DNA adduct levels have even been reported after heavy environmental PAH exposure. However, the results are very much dependent on the analytical method used, there is wide interindividual variation, and no clear cut quantitative relationship has been established between the adduct amounts and the level of exposure (20) - urinary aflatoxin DNA adducts being an exception (21). Thus, at present, no quantitative assessment of occupational chemical exposure can be performed from the analysis of DNA adducts.

\section{Health risk assessment}

A prerequisite for the use of biomarkers of exposure in health risk assessment is information on dose-effect and dose-response relationships. Such information can be obtained from epidemiologic investigations on the morbidity of populations with long-term exposure and longterm follow-up, or from clinical studies of populations with long-term exposure and long-term follow-up. In addition, it is required that representative biomonitoring data covering the whole period of exposure be available.

Reliable data of this type only exist on biomarkers of lead, cadmium, mercury, carbon monoxide, and fluoride (22). More limited data are available on arsenic (23). Among the macromolecule adducts, 1 study has indicated that the urinary concentration of aflatoxin $\mathrm{B}_{1}$-DNA adduct is predictive of the risk of hepatic cancer (24).

\section{Biomarkers of effect}

Biomarkers of effect comprise, for example, cholinesterase activities in plasma and erythrocytes, beta $a_{2}-m_{-}$ 
croglobulin in urine, or the number of polymorphonuclear granulocytes in bronchial lavage fluid. Biomarkers of effect are on the borderline between health surveillance (even diagnostics) and the monitoring of exposed populations. For several of the proposed markers, it is not clear that the marker is truly indicative of a nonadverse effect. Adverse effects cannot be used for routine monitoring, and such effects should not be tolerated in the first place. Biomarkers of genotoxic effects are discussed later in this presentation.

\section{Identification and quantitation of exposure}

Biomarkers of effect are, in principle, nonspecific as far as exposure is concerned. However, in occupational settings it is often possible to exclude other factors affecting biomarker levels, and thus a relative specificity is possible. For example, when cholinesterase analyses in blood or plasma are performed to identify people exposed to organophosphate insecticides, paired samples before and after exposure can be used to reduce individual variation in the enzyme activity as a source of error. Lead exposure can be effectively screened using erythrocyte protoporphyrin analyses (25).

Although mathematical relationships have been developed between erythrocyte protoporphyrin levels and blood lead levels, biomarkers of effect do not really aim at an estimation of exposure and have not been validated for this purpose either.

\section{Health risk assessment}

Changes in hem synthesis in bone marrow are well validated and have been extensively studied. However, it has not been demonstrated that their link to the critical neurophysiological effects of lead is closer than that of an integrated blood level value. They, especially protoporphyrin in erythrocytes, are analytically simple and have been successfully used. When accurate lead analysis is available, they do not offer advantages over blood-lead measurements.

Cholinesterase inhibition is easy to analyze, well validated, and has been extensively studied - and it has proved to be very useful in the prevention of cholinesterase poisoning. However, its relationship with low exposure and possible long-term effects is not clear-cut it may be that an analysis of alkylphosphates in urine may be more appropriate (26).

A large number of biological parameters has been studied as possible markers of adverse effects of chemicals on the kidney $(27-30)$. For some of them, the target locations in the kidney have been identified. In cadmium exposure, their health significance has also been elucidated (31). For other chemicals, the predictive value of renal effect markers is, however, practically unknown. In addition, the analysis of cadmium itself in urine has a good predictive value for kidney toxicity, and thus the main application of the different effect markers in health risk assessment would seem to be the identification of the few unusually susceptible people who exhibit kidney effects at cadmium levels at which the majority of the exposed do not suffer harm.

\section{Biomarkers of genotoxic effects}

The methods most often applied include cytogenetic methods, such as chromosome aberrations, micronuclei, and sister chromatid exchanges. There are also some studies on the application of point mutations, notably at the HPRT (hypoxanthine guanine phosphoribosyl transferase) locus. Especially the cytogenetic methods have, in several instances, been used successfully in the identification of exposed populations (although they are very nonspecific as far as the causative agent is concerned!) and in the follow-up of the efficacy of exposure-reducing measures. It is apparent that no quantitation of exposure can be achieved from these measurements. Furthermore, applying these markers requires careful planning, including a consideration of the reference populations. Thus they are ad hoc studies rather than routine biological monitoring.

An update report was recently published on cancer incidence and mortality in 2 European cohorts of people for whom chromosome aberrations, sister chromatid exchanges, and micronuclei had been analyzed (32). The people with the highest numbers of chromosome aberrations were at an elevated overall cancer risk - no such risk was observed for sister chromatid exchanges or micronuclei (for which the number of people studied and the average follow-up time were lower, however). It seems thus that chromosome aberration analysis has predictive value as far as cancer is concerned, and elevated levels indicate a group with an elevated risk.

An elevated frequency of HPRT mutations has been observed among cyclophosphamide production workers, and workers exposed to ethylene oxide, and styrene or dichloromethane, in lamination work. A correlation of HPRT with exposure and with adduct levels was observed among PAH-exposed foundry workers, and a correlation with individual adduct levels, but no overall elevation of the HPRT level, was found among garage workers (20). However, the inter- and intraindividual variation in the HPRT frequency is large; it is also dependent on age and affected by smoking $(33,34)$. Thus a positive finding for HPRT in a well-controlled monitoring program can be taken as an indicator of exposure, while a negative result does not exclude exposure, and no quantitation of exposure or effect is possible from the results. 


\section{Biomarkers of susceptibility}

There seem to be important differences in the sensitivity of different people to chemicals. In similar exposure circumstances, not all people encounter an adverse health effect and the severity of the effect varies between persons. Many environmental chemicals are toxic to the organism only after being transformed in the body to active chemical species, which are then detoxified by other enzyme-catalyzed reactions in the body. Thus, intuitively, it must be the balance between the enzymatic reactions that generate the active species and those that detoxify such active species that determines the toxic outcome in the body - and explains the differences in individual sensitivity.

For many chemicals, the reactions catalyzing activation and detoxification have been characterized, and there is intense research in progress on the application of the measurement of these enzyme activities or their proxies as biomarkers of susceptibility (ie, in assessing the sensitivity of different people to chemicals, or at least in identifying people that would be at a high or low risk if and when exposed.

Among the xenobiotic metabolizing enzymes that have been the most extensively studied as contributors to individual health (mainly cancer) risk are the different cytochrome P-450-dependent monooxygenases (CYP), glutathione S-transferases (GST), and N-acetyltransferases, out of which CYP have mostly an activating role, while the conjugating enzymes mainly play a detoxifying role, in the metabolism of chemicals. There is a recent surge in studies on xenobiotic metabolizing enzymes as biomarkers of susceptibility, mainly because of the possibilities to analyze the variations directly on bases other than phenotype (ie, enzyme activities), as has been done for decades already. It is however, by no means apparent that the genotype would reflect individual sensitivity better than the phenotype $(35,36)$.

$\mathrm{CYP}_{1 \mathrm{Al}}$ catalyses the activation of polycyclic aromatic hydrocarbons and is located mainly in tissues other than the liver. It is thus of interest in the carcinogenesis induced by a variety of occupational situations (coal gasification, foundries, aluminum production, coke production, exposure to coal tars and coal tar pitches, soots, tobacco smoke, etc). Correlations between $\mathrm{CYP}_{1 \mathrm{Al}}$ variants and lung cancer have been reported mainly in studies on southeast Asian populations $(37,38)$, but no similar clearcut picture emerges from studies performed in Europe or North America (39-44).

$\mathrm{CYP}_{2 \mathrm{D} 6}$ is another CYP variant for which several genetic variants have been described. It catalyzes the metabolism of several model substances which allow the determination of its activity in vivo. Although no role has been proposed for this CYP in the metabolism of known human carcinogens or occupational toxins, the relationship of its genotype and phenotype with many types of cancer has been extensively studied. No clear picture, however, has emerged (45-48).

Glutathione S-transferases are a family of enzymes that render electrophilic chemicals less reactive; they have generally rather low substrate specificity, and thus different variants can compensate low levels of other variants. Therefore, it is not surprising that studies on the relationship between different variants of GST M, P, and $T$ and diseases (mainly lung cancer among smokers) have all given rather uninterpretable results in that positive findings have been followed by completely negative reports in other populations $(38,41,49-55)$.

$\mathrm{N}$-acetylation is a step in the detoxification of aromatic amines (among others), several of which (eg, benzidine, aminobiphenyl, 2-naphthylamine, methylenebis(dichloroaniline)) are known as occupational carcinogens, and they mainly induce bladder cancer. Aromatic amines are also thought to cause increased bladder cancer incidence among smokers. Acetylation is catalyzed by the $\mathrm{N}$-acetyltransferases $\mathrm{NAT}_{1}$ and $\mathrm{NAT}_{2}$. There is a large number of studies on the relationship between the polymorphisms of $\mathrm{NAT}_{1}$ and $\mathrm{NAT}_{2}$ and the incidence of bladder cancer, and also some on colon cancer. Older studies on the phenotype based on the slow or fast acetylation of a model compound in vivo suggested that the risk of bladder cancer was higher among slow acetylators than it is among fast acetylators $(56-66)$; in some of the studies the difference was more marked when there was exposure to aromatic amines, such as occupational exposure or tobacco smoke. More recent studies on the genotype $\mathrm{NAT}_{2}$ and also of $\mathrm{NAT}_{1}$ seem to yield similar findings $(67-72)$. However, the relative risks have generally been rather low, less than 1.5 , and, in some studies, no association between acetylator status and bladder cancer risk has been observed among patients with or without presumed exposure to aromatic amines $(73,74)$. Furthermore, in several (but not all) studies, a relationship between colon cancer and acetylation status has been reported. Slow acetylators, who are thought to be at a low risk of urinary bladder cancer, seem to have an elevated risk for colon cancer (75-79).

When judging the information on the use of biomarkers, and especially the use of the polymorphism of xenobiotic metabolizing enzymes, as indicators of individual susceptibility, one should note that, first, most of the studies performed so far have had a poor assessment of exposure, and practically none have had a clear-cut, quantitated exposure to a single chemical. Thus there is a very important random misclassification which decreases the power of the study. Because of mixed exposure, one would expect only a part of the cancers observed to be due to the agent of interest (ie, to the agent, the metabolism of which is crucially catalyzed by the enzyme studied). Second, if and when there has been exposure 
to the chemicals of interest, the exposure has generally been low, and therefore also the expected relative risk of the disease has been low. Thus the fraction of the disease attributable to the agent of interest is low. Most cancers observed have been caused by factors other than the chemical of interest. Altogether, then, it is surprising that any positive findings have been reported so far. The question of the usefulness of biomarkers of susceptibility cannot be solved by simply analyzing the genetic polymorphism in existing tissue specimens of patients with a disease and comparing the results with data from healthy populations; rather, the tedious means of old-fashioned occupational epidemiology with strong emphasis on exposure assessment is called for.

It seems that, currently, biomarkers of susceptibility cannot be applied in the protection of workers against adverse health effects from exposure to chemicals. The specificity and sensitivity of all the present assays are far too weak for application on an individual level. Rather, the work conditions have to be such that all persons are protected. When the multiple exposures at the workplace, the multiplicity of parallel and competing enzymatic pathways for many xenobiotics in the body, the possible differences of rate-limiting steps in the enzymatic pathways at different levels of exposure, and the difficulties in epidemiologic validation studies are considered, it is unlikely that major steps forward can be taken during the next few years. The situation may be different on the scale of insurance mathematics since even low relative risks may be reflected as large amounts of money when applied to big population groups. This application of biomarkers of susceptibility has nothing to do however with the protection of the worker - the worker should be protected against such use of biomarkers.

\section{Future trends}

The development of biomarkers, and especially their application in worker health protection, depends on changes in society and the balance of forces therein.

There is a marked trend toward "liberalization" in Western societies, meaning that the fittest survive and the societal safety nets are disbanded. At the workplace this trend leads to decreasing regulation and emphasis on maximal productivity. If this development continues, there will be less and less worker health protection and biomonitoring will shrink to an occasional analysis of lead in blood.

There is also a trend toward a society of ubiquitous litigation - and litigation where time sequence of events is considered to prove causality. This trend will lead to a need to demonstrate that no exposure took place at the workplace - and, since the only means of proving nonexposure is biomonitoring, to a greatly increased need for biomarker use. It is clear that, since the litigation society is in a world of liberalization, an alternative is to transfer all manufacturing to areas where litigation is not possible, and where the unionization of the worker is not possible - and where little worker protection and no biomonitoring exist.

In contrast to these rather gloomy perspectives, the realization of the healthy worker as a major asset in the enterprise (ie, acceptance of the fact that, in the longterm, worker health protection is a good investment) is also increasing. This trend will lead to an increasing demand for biomarker use. However, in the world of economic realities, there is also an accentuated requirement for useful results of activities. Therefore uninterpretable figures from biomonitoring will not be paid for. There will be heavy pressure to come up with a useful interpretation of every analysis. Thus the validity - in terms of the prediction of health effects or quantitative exposure assessment - is a prerequisite for each biomarker.

The requirement of validity is especially conspicuous in the case of markers of susceptibility, because, at present, it is very limited if nonexistent for the purpose of the protection of an individual worker. Unless validity can be convincingly demonstrated, and application in the interest of the worker can be guaranteed, biomarkers of susceptibility have no place in occupational health.

Major advances in validation can only be derived from long-term follow-up studies with proper epidemiologic design. A major challenge of occupational toxicology is research into exposure-response relationships on end points other than those available on death certificates. Perhaps the most pressing is the need to work on central nervous system effects - in view of the huge burden of diseases such as Alzheimer's on the individual and society.

In the short-term, important advances may be made in the assessment of the quantitative relationship between exposure and biomarkers. Such advances can then indirectly be used in the assessment of health risks. A major challenge is the investigation of the quantitation of dermal exposure. It would seem likely that inhalation exposure, especially of volatile chemicals (in contrast to aerosols), will be equally well assessed by personal breathing-zone air analysis.

The development of biomonitoring in recent years has mainly been driven by the development of analytical capabilities. Sensitive and specific analytical methods have been developed which allow the accurate measurement of many chemicals of occupational exposure interest in biological specimens. However, this development has also led to the application of more and more expensive (time, expertise, and instrumentation) analytical methodologies - to an extent that cost is the biggest hurdle in doing effective biomonitoring, especially in the case of chemicals with short half-times in the body, where only 
frequent analyses can guarantee the absence of high exposures. If biomonitoring is to survive as a routine means of exposure or risk assessment, analytical methods have to be developed that cost next to nothing per analysis. Such analyses can be used to screen for exposure. They will be less specific than the present methods, and they will only yield semiquantitative data on whether there has been significant exposure or not. Such methods will be applied (very) frequently, say after every workday. Whenever they indicate excessive exposure, the day's exposure will be reviewed, and corrective actions introduced. If judged to be necessary, the high-tech analyses of today will be used to verify, exclude, or quantify the exposure. The most likely avenues leading to such analytical methods are immunologic and receptor binding assays, which have been extensively used in clinical pharmacology, clinical chemistry, and even environment analysis.

The application of biomarkers in occupational health has, to a great extent, taken the form of continuous or repetitive monitoring ( 80 ). If the development of lowcost biomarkers for semiquantitative exposure monitoring is not successful, the resources for biomonitoring would be utilized better in an initial, extensive, and intensive assessment of the exposure at the workplace and technical assurance that the exposures will be continuously low, with only occasional verificative analyses rather than in continuous automatic and monotonous monitoring.

\section{Acknowledgments}

I am grateful to Dr Vesa Riihimäki for his useful discussions and suggestions.

\section{References}

1. Committee on Biological Markers of the National Research Council. Biological markers in environmental health research. Environ Health Perspect 1987;74:3-9.

2. International Programme on Chemical Safety (IPCS). Biomarkers and risk assessment: concepts and principles. Geneva: World Health Organization, 1993. Environmental health criteria, no 155.

3. Bartoluzzi GB, De Rosa E, Cori GP, Corona PC, Perbellini L, Brugnone F. Biomonitoring of occupational exposure to styrene. Appl Ind Hyg 1986;3:125-31.

4. Elia VJ, Anderson LA, MacDonald TJ, Carson A, Buncher $\mathrm{CR}$, Brooks SM. Determination of urinary mandelic and phenylglyoxylic acids in styrene exposed workers and a control population. Am Ind Hyg Assoc J 1980;41:922-6.

5. Engström K, Härkönen H, Pekari K, Rantanen J. Evaluation of occupational styrene exposure by ambient air and urine analysis. Scand J Work Environ Health 1978;2 suppl 2:1213.
6. Franchini I, Angiolini A, Arcari C, Falzoi M, Ferrari C, Ferri $\mathrm{F}$, et al. Mandelic acid and phenylglyoxylic acid excretion in workers exposed to styrene under model conditions. In: Hayes AW, Schnell RC, Miya TS, editors. Developments in science and practice of toxicology. Amsterdam: Elsevier Science Publishers BV, 1983:567-70.

7. Guillemin MP, Bauer D, Martin B, Marazzi A. Human exposure to styrene IV: industrial hygiene investigations and biological monitoring in the polyester industry. Int Arch Occup Environ Health 1982;51:139-50.

8. Pekari K, Nylander-French L, Pfäffli P, Sorsa M, Aitio A. Biological monitoring of exposure to styrene - assessment of different approaches. J Occup Med Toxicol 1993;2:11526.

9. Casal Lareo A, Perbellini L. Biological monitoring of workers exposed to $\mathrm{N}, \mathrm{N}$ - dimethylformamide II: dimethylformamide and its metabolites in urine of exposed workers. Int Arch Occup Environ Health 1995;67:47—52.

10. Kawai T, Yasugi T, Mizunuma K, Watanabe T, Cai S-X, Huang $\mathrm{M}-\mathrm{Y}$, et al. Occupational dimethylformamide exposure 2. Monomethylformamide excretion in urine after occupational dimethylformamide exposure. Int Arch Occup Environ Health 1992;63:455-60.

11. Lauwerys RR, Kivits A, Lhoir M, Rigolet P, Houbeau D, Buchet JP, et al. Biological surveillance of workers exposed to dimethylformamide and the influence of skin protection on its percutaneous absorption. Int Arch Occup Environ Health 1980;45:189-203.

12. Sakai T, Kageyama H, Araki T, Yosida T, Kuribayashi T, Masuyama Y. Biological monitoring of workers exposed to $\mathrm{N}, \mathrm{N}$-dimethylformamide by determination of the urinary metabolites, $\mathrm{N}$-methylformamide and $\mathrm{N}$-acetyl-S-(N-methylcarbamoyl) cysteine. Int Arch Occup Environ Health 1995;67:125-9.

13. Sala C, Bernabeo F, Colombo G, Invernizzi E, Meneghel G. Dimethylformamide risk: an evaluation in the production of artificial organic leather. G Ital Med Lav 1984;6:143-8.

14. Health and Safety Executive. Biological monitoring for chemical exposures in the workplace: guidance note EH 56 from the Health and Safety Executive. London: Her Majesty's Stationery Office, 1992.

15. Toniolo P, Boffetta P, Shuker DEG, Rothman N, Hulka B, Pearce N, editors. Application of biomarkers in cancer epidemiology. Lyon (France): International Agency for Research on Cancer (IARC), 1997. IARC scientific publications, no 142.

16. Kensler TW, Groopman JD, Sutter TR, Curphey TJ, Roebuck BD. Development of cancer chemopreventive agents: Oltipraz as a paradigm. Chem Res Toxicol 1999;12:113-26.

17. Deutsche Forschungsgemeinschaft (DFG). MAK- und BATWerte-Liste 1996: Senatskommission zur Prüfung gesundheitsschädlicher Arbeitsstoffe. 32nd ed. Weinheim (BRD): VCH Verlagsgesellschaft mbH, 1996.

18. Osterman-Golkar S, Bond JA. Biomonitoring of 1,3-butadiene and related compounds. Environ Health Perspect 1996:104 supp1 5:907-15.

19. Shuker DEG. DNA adducts in mammalian cells as indicators of exposure to carcinogens. In: McGregor DB, Rice JM, Venitt $S$, editors. The use of short- and medium-term tests for carcinogens and data on genetic effects in carcinogenic hazard evaluation. Lyon (France): International Agency for Research on Cancer (IARC), 1999:287-308. IARC scientific publications, no 146 .

20. Hemminki K. Biomarkers of exposure and effect for carcino- 
genicity. In: Anonymous, editor. Environmental health criteria document biomarkers in risk assessment: validity and validation. Geneva: World Health Organization. In press.

21. Groopman JD. Molecular dosimetry methods for assessing human aflatoxin exposures. In: Eaton DA, Groopman JD, eds. The toxicology of aflatoxins, human health, veterinary and agricultural significance. San Diego (CA): Academic Press, 1994:259-79.

22. World Health Organization (WHO). Biological monitoring of chemical exposure in the workplace; vol 1. Geneva: WHO, 1996.

23. Aitio A, Hakala E, Pyy L. Arsenic. In: Anonymous, editor. Guidelines on biological monitoring of chemical exposure at the workplace; vol 2. Geneva: World Health Organization, 1996:18-34.

24. Qian G-S, Ross RK, Yu MC, Yuan J-M, Gao Y-T, Henderson $\mathrm{BE}$, et al. A follow-up study of urinary markers of aflatoxin exposure and liver cancer risk in Shanghai, People's Republic of China. Cancer Epidemiol Biomarkers Prev 1994;3 suppl $5: 3-10$.

25. Schaller KH. Inorganic lead. In: Anonymous, editor. Biological monitoring of chemical exposure at the workplace, vol 1. Geneva: World Health Organization, 1996:112-31.

26. Gompertz D, Verschoyle RD. Organophosphorus pesticides. In: Anonymous, editor. Guidelines on biological monitoring of chemical exposure at the workplace; vol 1. Geneva, Switzerland: World Health Organization, 1996:237-63.

27. Cárdenas A, Roels H, Bernard A, Barbon R, Buchet JP, Lauwerys RR, et al. Markers of early renal changes induced by industrial pollutants, I: application to workers exposed to mercury vapour. $\mathrm{Br} \mathrm{J}$ Ind Med 1993;50:17-27.

28. Cárdenas A, Roels H, Bernard A, Barbon R, Buchet JP, Lauwerys RR, et al. Markers of early renal changes induced by industrial pollutants, II: application to workers exposed to lead. Br J Ind Med 1993;50:28 - 36.

29. Roels H, Bernard AM, Cárdenas A, Buchet JP, Lauwerys RR, Hotter $G$, et al, Markers of early renal changes induced by industrial pollutants, III: application to workers exposed to cadmium. Br J Ind Med 1993;50:37-48.

30. Bernard A. Sections 3.1.9 - 3.1.11 $\beta 2$-microglobulin, retinol binding globulin, and alpha1-microglobulin in urine. In: Anonymous, editor. Biological monitoring of chemical exposure at the workplace; vol 1. Geneva: World Health Organization, 1996:74-90.

31. Mutti A. Biomarkers of exposure and effect for non-carcinogenic end-points. In: Anonymous, editor. Environmental health criteria document biomarkers in risk assessment: validity and validation. Geneva: World Health Organization. In press.

32. Hagmar L, Bonassi S, Stromberg U, Brogger A, Knudsen LE, Norppa $\mathbf{H}$, et al. Chromosomal aberrations in lymphocytes predict human cancer: a report from the European Study Group on Cytogenetic Biomarkers and Health (ESCH). Cancer Res 1998;58:4117-21.

33. Cole J, Skopek TR. International Commission for Protection against Environmental Mutagens and Carcinogens, working paper 3: somatic mutant frequency, mutation rates and mutational spectra in the human population in vivo. Mutat Res 1994:304:33-106.

34. Albertini RJ, Hayes RB. Somatic cell mutations in cancer epidemiology. In: Toniolo P, Boffetta P, Shuker DEG, Rothman N, Hulka B, Pearce N, editors. Application of biomarkers in cancer epidemiology. Lyons: International Agency for Research on Cancer (IARC), 1997:159-84. IARC Scientific
Publications, no 142

35. Raunio H, Husgafvel-Pursiainen K, Anttila S, Hietanen E, Hirvonen A, Pelkonen O. Diagnosis of polymorphisms in carcinogen-activating and incativating enzyémes and cancer susceptibility - a review. Gene 1995;159:113-21.

36. Pelkonen $\mathrm{O}$, Raunio H, Lang M. Xenobiotic-metabolizing enzymes and cancer risk: correspondence between genotype and phenotype. In: Vineis P, Malats N, Lang M, d'Errico A, Caporaso N, Cuzick J, et al, editors. Metabolic polymorphisms and cancer. Lyons: International Agency for Research on Cancer (IARC), 1999:77-88. IARC scientific publications, no 148.

37. Sugimura $H$, Wakai $K$, Genka $K$, Nagura K, Igarashi $H$, Nagayama K, et al. Association of Ile462Val (Exon 7) polymorphism of cytochrome P450 IA1 with lung cancer in the Asian population: further evidence from a case-control study in Okinawa. Cancer Epidemiol Biomarkers Prev 1998;7:413-7.

38. Hong YS, Chang JH, Kwon OJ, Ham YA, Choi JH. Polymorphism of the CYP1A1 and glutathione-S-transferase gene in Korean lung cancer patients. Exp Mol Med (Seoul) 1998; 30:192-8.

39. Xu X, Kelsey KT, Wiencke JK, Wain JC, Christiani DC. Cytochrome P450 CYP1A1 MspI polymorphism and lung cancer susceptibility. Cancer Epidemiol Biomarkers Prev 1996:5:687-92.

40. Taioli E, Ford J, Trachman J, Li Y, Demopoulos R, Garte S. Lung cancer risk and CYP1Al genotype in African Americans. Carcinogenesis 1998;19:813-7.

41. Garcia-Closas M, Kelsey KT, Wiencke JK, Xu X, Wain JC, Christiani DC. A case-control study of cytochrome P450 1A1, glutathione S-transferase M1, cigarette smoking and lung cancer susceptibility (Massachusetts, United States) [published erratum appears in Cancer Causes Control 1998 Jan;9(1):126] Cancer Causes Control 1997;8:544-53.

42. Kelsey KT, Wiencke JK, Spitz MR. A race-specific genetic polymorphism in the CYP1A1 gene is not associated with lung cancer in African Americans. Carcinogenesis 1994;15:1121-4.

43. London SJ, Daly AK, Cooper J, Carpenter CL, Navidi WC, Ding L, Idle JR. Lung cancer risk in relation to the CYP2E1 Rsa I genetic polymorphism among African-Americans and Caucasians in Los Angeles County. Pharmacogenetics 1996;6:151-8.

44. Hirvonen A, Husgafvel-Pursiainen K, Anttila S, Karjalainen A, Vainio H. Polymorphism in CYP1A1 and CYP2D6 genes: possible association with susceptibility to lung cancer. Environ Health Perspect 1993;101 suppl 3:109-12.

45. Rostami-Hodjegan A, Lennard MS, Woods HF, Tucker GT Meta-analysis of studies of the CYP2D6 polymorphism in relation to lung cancer and Parkinson's disease. Pharmacogenetics 1998;8:227-38.

46. Christensen PM, Gotzsche PC, Brosen K. The sparteine/debrisoquine (CYP2D6) oxidation polymorphism and the risk of lung cancer: a meta-analysis. Eur J Clin Pharmacol 1997;51:389-93.

47. Legrand-Andreoletti M, Stucker I, Marez D, Galais P, Cosme J, Sabbagh N, et al. Cytochrome P450 CYP2D6 gene polymorphism and lung cancer susceptibility in Caucasians. Pharmacogenetics 1998;8:7-14.

48. Shaw GL, Falk RT, Frame JN, Weiffenbach B, Nesbitt JC, Pass HI, et al. Genetic polymorphism of CYP2D6 and lung cancer risk. Cancer Epidemiol Biomarkers Prev 1998;7:2159. 
49. Nyberg F, Hou SM, Hemminki K, Lambert B, Pershagen G. Glutathione S-transferase mul and $\mathrm{N}$-acetyltransferase 2 genetic polymorphisms and exposure to tobacco smoke in nonsmoking and smoking lung cancer patients and population controls. Cancer Epidemiol Biomarkers Prev 1998;7:87583.

50. Salagovic J, Kalina I, Stubna J, Habalova V, Hrivnak M, Valansky L, et al. Genetic polymorphism of glutathione $\mathbf{S}$ transferases $\mathrm{M} 1$ and $\mathrm{T} 1$ as a risk factor in lung and bladder cancers. Neoplasma 1998;45:312-7.

51. Kelsey KT, Spitz MR, Zuo ZF, Wiencke JK. Polymorphisms in the glutathione $S$-transferase class $\mathrm{mu}$ and theta genes interact and increase susceptibility to lung cancer in minority populations (Texas, United States). Cancer Causes Control $1997 ; 8: 554-9$.

52. Jourenkova-Mironova N, Wikman H, Bouchardy C, Voho A, Dayer P, Benhamou S, Hirvonen A. Role of glutathione Stransferase GSTM1, GSTM3, GSTP1 and GSTT1 genotypes in modulating susceptibility to smoking-related lung cancer. Pharmacogenetics 1998;8:495-502.

53. Saarikoski ST, Voho A, Reinikainen M, Anttila S, Karjalainen A, Malaveille C, et al. Combined effect of polymorphic GST genes on individual susceptibility to lung cancer. Int $\mathrm{J}$ Cancer 1998;77:516-21.

54. Harrison DJ, Cantlay AM, Rae F, Lamb D, Smith CA. Frequency of glutathione S-transferase M1 deletion in smokers with emphysema and lung cancer. Hum Exp Toxicol 1997;16:356-60

55. To-Figueras J, Gene M, Gomez-Catalan J, Galan MC, Fuentes M, Ramon JM, et al. Glutathione S-transferase M1 (GSTM1) and T1 (GSTT1) polymorphisms and lung cancer risk among Northwestern Mediterraneans. Carcinogenesis 1997; 18:1529-33.

56. Lower GMJ, Nilsson T, Nelson CE, Wolf H, Gamsky TE, Bryan GT. N-Acetyltransferase phenotype and risk in urinaréy bladder cancer: approaches in molecular epidemiology. Preliminary results in Sweden and Denmark. Environ Health Perspect 1979;29:71-9.

57. Miller ME. Acetylator phenotype in bladder cancer. Lancet $1982 ; 2: 1348$.

58. Mommsen S, Sell A, Barfod N. N-Acetyltransferase phenotypes of bladder cancer patients in a low-risk population. Lancet $1982 ; 2: 1228$.

59. Cartwright RA, Glashan RW, Rogers HJ, Ahmad RA, Barham-Hall D, Higgins E, et al. Role of $\mathrm{N}$-acetyltransferase phenotypes in bladder carcinogenesis: a pharmacogenetic epidemiological approach to bladder cancer. Lancet $1982 ; 2: 842-6$.

60. Evans DA, Eze LC, Whibley EJ. The association of the slow acetylator phenotype with bladder cancer. J Med Genet 1983;20:330-3.

61. Wolf H, Lower GM Jr, Bryan GT. Role of N-acetyltransferase phenotype in human susceptibility to bladder carcinogenic arylamines. Scand J Urol Nephrol 1980;14:161-5.

62. Woodhouse KW, Adams PC, Clothier A, Mucklow JC, Rawlins $\mathrm{MD}$. $\mathrm{N}$-acetylation phenotype in bladder cancer. Hum Toxicol 1982;1:443-5.

63. Mommsen S, Aagaard J. Susceptibility in urinary bladder cancer: acetyltransferase phenotypes and related risk factors. Cancer Lett 1986;32:199_205.

64. Mommsen S, Barfod NM, Aagaard J. N-Acetyltransferase phenotypes in the urinary bladder carcinogenesis of a low-risk population. Carcinogenesis 1985;6:199-201.

65. Hanssen HP, Agarwal DP, Goedde HW, Bucher H, Huland H,
Brachmann W, et al. Association of N-acetyltransferase polymorphism and environmental factors with bladder carcinogenesis: study in a north German population. Eur Urol $1985 ; 11: 263-6$.

66. Ladero JM, Kwok CK, Jara C, Fernandez L, Silmi AM, Tapia D, Uson AC. Hepatic acetylator phenotype in bladder cancer patients. Ann Clin Res 1985;17:96-9.

67. Taylor JA, Umbach DM, Stephens E, Castranio T, Paulson D, Robertson $\mathrm{C}$, et al. The role of $\mathrm{N}$-acetylation polymorphisms in smoking-associated bladder cancer: evidence of a genegene-exposure three-way interaction. Cancer Res 1998;58:3603-10.

68. Schnakenberg E, Ehlers C, Feyerabend W, Werdin R, Hubotter R, Dreikorn K, et al. Genotyping of the polymorphic Nacetyltransferase (NAT2) and loss of heterozygosity in bladder cancer patients. Clin Genet 1998;53:396-402.

69. Filiadis IF, Georgiou I, Alamanos Y, Kranas V, Giannakopoulos X, Lolis D. Genotypes of N-acetyltransferase- 2 and risk of bladder cancer: a case-control study [In Process Citation]. J Urol 1999;161:1672-5 [MEDLINE record in process].

70. Golka K, Reckwitz T, Kempkes M, Cascorbi I, Blaskewicz M, Reich SE, et al. N-Acetyltransferase 2 (NAT2) and glutathione S-transferase (GSTM1) in bladder-cancer patients in a highly industrialized area. Int J Occup Environ Health 1997;3:105-10 [Record as supplied by publisher].

71. Golka K, Prior V, Blaszkewicz M, Cascorbi I, Schops W, Kierfeld $\mathrm{G}$, et al. Occupational history and genetic $\mathrm{N}$-acetyltransferase polymorphism in urothelial cancer patients of Leverkusen, Germany. Scand J Work Environ Health 1996;22:332-8.

72. Okkels H, Sigsgaard T, Wolf H, Autrup H. Arylamine Nacetyltransferase 1 (NAT1) and 2 (NAT2) polymorphisms in susceptibility to bladder cancer: the influence of smoking. Cancer Epidemiol Biomarkers Prev 1997;6:225-31.

73. Hayes RB, Bi W, Rothman N, Broly F, Caporaso N, Feng P, et al. $\mathrm{N}$-acetylation phenotype and genotype and risk of bladder cancer in benzidine-exposed workers. Carcinogenesis 1993; $14: 675-8$.

74. Miller ME, Cosgriff JM. Acetylator phenotype in human bladder cancer. J Urol 1983;130:65-6.

75. Welfare MR, Cooper J, Bassendine MF, Daly AK. Relationship between acetylator status, smoking, and diet and colorectal cancer risk in the north-east of England. Carcinogenesis $1997 ; 18: 1351-4$.

76. Roberts-Thomson IC, Ryan P, Khoo KK, Hart WJ, McMichael AJ, Butler RN. Diet, acetylator phenotype, and risk of colorectal neoplasia. Lancet 1996;347:1372 - 4.

77. Chen J, Stampfer MJ, Hough HL, Garcia-Closas M, Willett WC, Hennekens $\mathrm{CH}$, et al. A prospective study of $\mathrm{N}$-acetyltransferase genotype, red meat intake, and risk of colorectal cancer. Cancer Res 1998;58:3307-11.

78. Slattery ML, Potter JD, Samowitz W, Bigler J, Caan B, Leppert M. NAT2, GSTM-1, cigarette smoking, and risk of colon cancer. Cancer Epidemiol Biomarkers Prev 1998;7:107984.

79. Probst-Hensch NM, Haile RW, Li DS, Sakamoto GT, Louie $\mathrm{AD}$, Lin BK, et al, Lack of association between the polyadenylation polymorphism in the NAT1 (acetyltransferase 1) gene and colorectal adenomas. Carcinogenesis 1996; 17:2125-9.

80. Berlin A, Yodaiken RE, Henman BA, editors. Assessment of toxic agents at the workplace: roles of ambient and biological monitoring. The Hague: Martinus Nijhoff Publishers, 1984. 